\title{
KILAT
}

Vol. 9, No. 1, April 2020, P-ISSN 2089-1245, E-ISSN 2655-4925

DOI: https://doi.org/10.33322/kilat.v9i1.767

\section{Radiolink Microwave Sebagai Infrastruktur Telekomunikasi Sistem SCADA}

\author{
Suhardhika Sih Sudewanto \\ PT. PLN (Persero) PUSDIKLAT, UPDL Pandaan, Indonesia \\ suhardhika@gmail.com
}

\begin{abstract}
Expansion of the electrical network and substation makes a demand of the telecommunication channel for SCADA system is high. Telecommunication infrastructure which operates based on Power Line Carrier (PLC) can not provide adequate supply. Therefore, It needs new media to fulfill the demands of the telecommunication channel for SCADA System. Selection methods will be done by comparing technical and non-technical aspects of various telecommunication media that operates in the PLN network. One of suitable media is microwave radiolink. With high capacity and bandwidth, microwave radiolink can be the backbone of SCADA System
\end{abstract}

Keywords: telecommunication infrastructure, microwave radiolink

\begin{abstract}
ABSTRAK
Perluasan jaringan dan penambahan gardu induk menyebabkan kebutuhan kanal untuk sistem SCADA menjadi tinggi. Infrastruktur telekomunikasi yang bertumpu pada Power Line Carrier (PLC) sudah tidak mampu mencukupi hal tersebut. Untuk itu diperlukan media telekomunikasi baru untuk memenuhi kebutuhan kanal komunikasi sistem SCADA. Metode pemilihan media telekomunikasi ditentukan dengan cara membandingkan aspek teknis dan nonteknis berbagai macam media komunikasi di lingkungan kerja PLN. Salah satu media telekomunikasi yang cocok adalah radiolink microwave. Dengan kapasitas dan bandwidth yang besar, radiolink microwave dapat dijadikan sebagai backbone sistem SCADA.
\end{abstract}

Kata kunci: infrastruktur telekomunikasi, radiolink microwave 


\section{Pendahuluan}

Pengembangan sistem SCADA tidak akan terlepas dari permasalahan sistem telekomunikasi. Sistem telekomunikasi yang baik, harus mampu memenuhi kebutuhan kanal komunikasi secara kuantitas maupun secara kualitas. Sistem telekomunikasi yang baik akan membuat sistem SCADA berjalan efektif dan handal.

Sistem SCADA yang menggunakan PLC untuk sistem telekomunikasi akan mengalami kesulitan untuk berkembang seiring dengan bertambahnya jumlah gardu induk. Metode penambahan link PLC sudah tidak efektif lagi karena akan terbentur pada keterbatasan jumlah 2 kanal per link dan frekuensi kerja PLC di 50-500 KHz. Untuk mengatasi hal ini, perlu pembangunan jalur telekomunikasi broadband.

Sistem telekomunikasi broadband adalah sistem telekomunikasi yang mempunyai bandwidth lebar dan mempunyai kapasitas transfer data setara atau lebih besar dari 1,54 Mbps (T1-North American Standard)[1] atau $2 \mathrm{Mbps}$ (E1-European Standard). Media yang mendukung sistem telekomunikasi broadband contohnya serat optik [2][3], VSAT [4] dan radiolink microwave[5]. Perangkat yang kompatibel atau mendukung sistem telekomunikasi broadband contohnya multiplexer dan switch.

\section{Metode Pemilihan Media dan Perencanaan Pemanfaatan}

PLN Area Penyaluran dan Pengatur Beban (AP2B) Sistem Sulawesi Selatan menggunakan PLC sebagai infrastruktur telekomunikasi sistem SCADA[6]. Dengan keterbatasan PLC, mereka harus memiliki media telekomunikasi baru. Metode pemilihan media komunikasi dilakukan dengan membandingkan aspek teknis dan non teknis berbagai macam media komunikasi broadband yang umum dipakai di lingkungan kerja PLN sesuai Tabel 1. Selanjutnya pemilihan media harus mendapat persetujuan manajemen untuk dieksekusi.

Tabel 1. Perbandingan Media Telekomunikasi

\begin{tabular}{|c|c|c|}
\hline $\begin{array}{c}\text { JENIS } \\
\text { MEDIA }\end{array}$ & KELEBIHAN & KEKURANGAN \\
\hline $\begin{array}{l}\text { Serat } \\
\text { Optik }\end{array}$ & $\begin{aligned}> & \text { Kapasitas tinggi } \\
> & \text { Bandwidth lebar } \\
> & \text { Delay rendah } \\
> & \text { Variasi dan } \\
& \text { potensi utilisasi } \\
& \text { aplikasi sangat } \\
& \text { luas } \\
> & \text { Resisten } \\
& \text { terhadap } \\
& \text { interferensi dan } \\
& \text { noise } \\
& \text { elektromagnetik }\end{aligned}$ & $\begin{aligned}> & \text { Biaya tinggi } \\
& \text { untuk investasi } \\
& \text { peralatan dan } \\
\text { teknologi } & \\
> & \text { Rentan secara } \\
& \text { fisik }\end{aligned}$ \\
\hline
\end{tabular}




\section{KILAT}

Vol. 9, No. 1, April 2020, P-ISSN 2089-1245, E-ISSN 2655-4925

DOI: https://doi.org/10.33322/kilat.v9i1.767

\begin{tabular}{|c|c|c|c|}
\hline VSAT & $\begin{aligned} & \text { Kapasitas tinggi } \\
> & \text { Bandwidth lebar } \\
> & \text { Cocok untuk } \\
& \text { daerah terpencil }\end{aligned}$ & $>$ & $\begin{array}{l}\text { Delay dan } \\
\text { redaman } \\
\text { tinggi } \\
\text { Biaya } \\
\text { operasional } \\
\text { tinggi }\end{array}$ \\
\hline $\begin{array}{l}\text { Radiolink } \\
\text { Micro } \\
\text { wave }\end{array}$ & $\begin{aligned}> & \text { Kapasitas tinggi } \\
> & \text { Bandwidth lebar } \\
> & \text { Delay rendah } \\
> & \text { Variasi dan } \\
& \text { potensi utilisasi } \\
& \text { aplikasi cukup } \\
& \text { luas } \\
> & \text { Biaya investasi } \\
& \text { dan operasional } \\
& \text { tidak terlalu } \\
& \text { tinggi }\end{aligned}$ & $>$ & $\begin{array}{l}\text { Potensi } \\
\text { interferensi } \\
\text { dan noise } \\
\text { tinggi (cuaca, } \\
\text { gangguan } \\
\text { elektromagne } \\
\text { tik skala } \\
\text { besar) } \\
\text { Tidak semua } \\
\text { aplikasi } \\
\text { mampu } \\
\text { diterapkan }\end{array}$ \\
\hline
\end{tabular}

Sesuai persetujuan manajemen, radiolink microwave adalah opsi yang paling feasible untuk dilaksanakan. Terdapat 2 langkah penting untuk pembangunan radiolink microwave, yaitu proses survei dan perijinan serta penentuan spesifikasi alat/teknologi yang digunakan

Survei memegang peranan sangat penting untuk memperoleh link budget radio. Link budget radio adalah hasil tes link microwave yang berisi berbagai macam informasi yang menentukan kualitas layanan radio. Informasi ini diantaranya adalah besarnya path loss (rugi transmisi), besarnya noise dan fade margin (besarnya margin yang dibutuhkan untuk menutup adanya kemungkinan kerusakan sinyal akibat fenomena multipath) dan Bit Error Rate[7]. Link budget radio akan menentukan layak tidaknya suatu site untuk ditempati peralatan radiolink microwave.

Ada 2 pilihan penggunaan spektrum frekuensi untuk microwave, yaitu frekuensi publik (umum, tidak memerlukan ijin) dan frekuensi berlisensi (memiliki ijin). Frekuensi publik memiliki frekuensi di kisaran 2,4 GHz dan 5,8 GHz.

Sedangkan frekuensi berlisensi memiliki range mulai dari Very Low Frequency sampai dengan Extremely High Frequency[8] yang penerapannya disesuaikan dengan peraturan perundangan yang berlaku[9]. Frekuensi publik sifatnya gratis atau tanpa biaya, tapi penggunaan frekuensi publik akan mengakibatkan sistem rentan terhadap gangguan interferensi dari peralatan lain. Penggunaan frekuensi berlisensi relatif lebih stabil terhadap gangguan dan lebih kuat posisinya ditinjau dari segi hukum, tapi ada biaya yang harus dibayarkan tiap tahun [10][11].

Peralatan microwave terdiri dari peralatan outdoor dan indoor. Peralatan outdoor terdiri dari antenna dan kabel koaksial. Sedangkan peralatan indoor terdiri dari modul radiolink microwave dan multiplexer dengan slot tambahan untuk berbagai aplikasi yang sifatnya opsional. Desain radiolink microwave ditunjukkan oleh Gambar 1. 


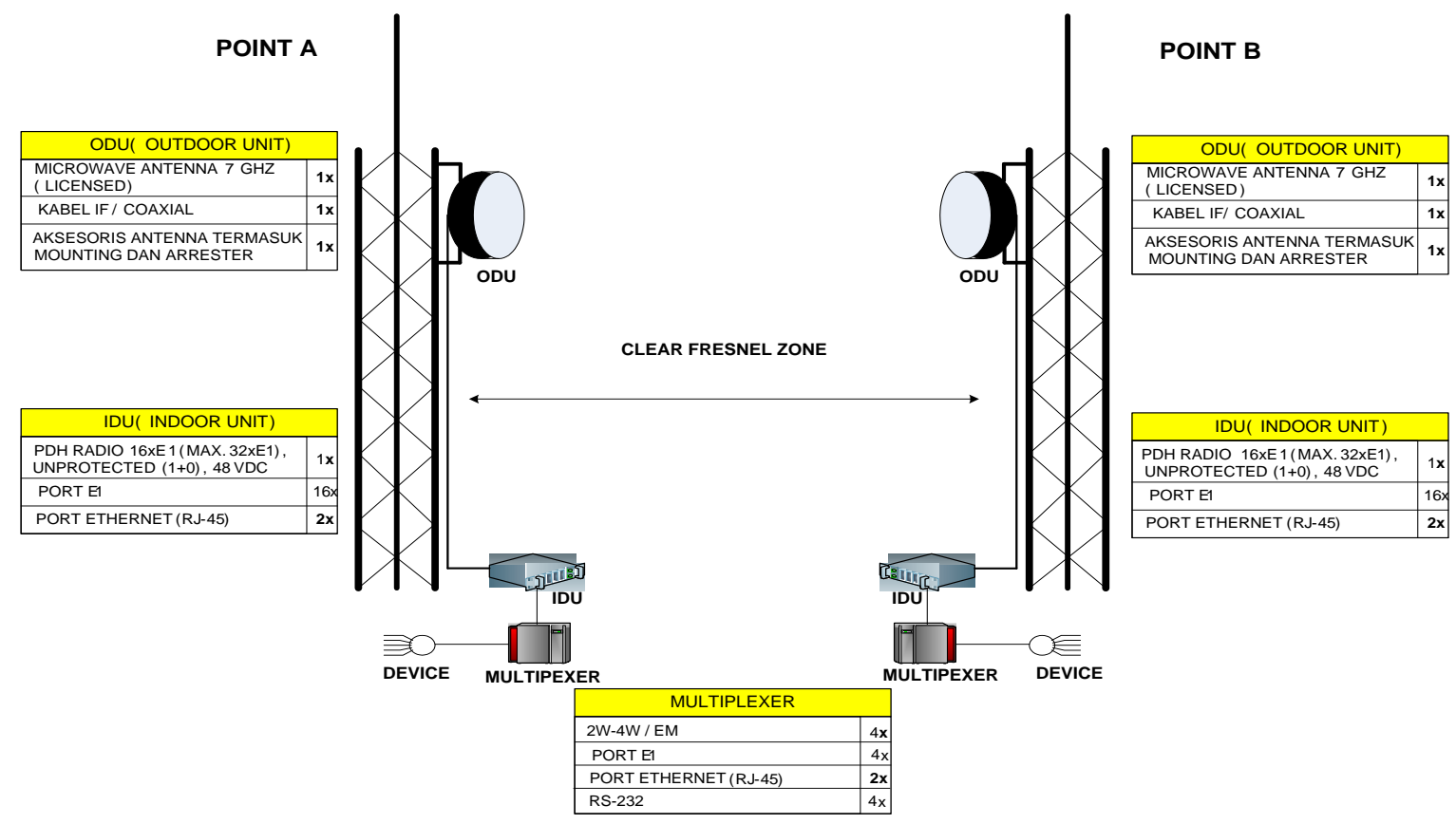

Gambar 1. Radiolink Microwave

Sebelum ditransmisikan oleh radiolink microwave, fungsi voice dan data dipetakan oleh multiplexer. Pembagian kanal untuk masing-masing fungsi dilakukan di slot opsional multiplexer. Slot opsional mempunyai model interface yang bisa dipilih. Pilihan interface bisa berupa RS-232, 4wire, 2-wire atau LAN port.

Teknologi transport data bisa menggunakan PDH (Plesiochronous Digital Hierarchy) atau SDH (Synchronous Digital Hierarchy). Teknologi PDH merupakan teknologi lama yang lebih cocok digunakan untuk jaringan yang tidak terlalu besar. Sedangkan teknologi SDH lebih bagus dipakai untuk kapasitas data besar dan konfigurasi network yang rumit. Satu modul transport data E1 mampu menyediakan 30 kanal dengan kapasitas masing-masing sebesar 64 kbps.

\section{Pelaksanaan Pembangunan}

Pembangunan radio microwave dilaksanakan di Control Center (AP2B), GI Daya, GI Mandai dan GI Sungguminasa. Pemasangan dilakukan setelah dilakukan survei dan perhitungan link budget. Link budget di tiga titik tersebut sesuai Gambar 2, Gambar 3 dan Gambar 4. 


\section{KILAT}

Vol. 9, No. 1, April 2020, P-ISSN 2089-1245, E-ISSN 2655-4925

DOI: https://doi.org/10.33322/kilat.v9i1.767

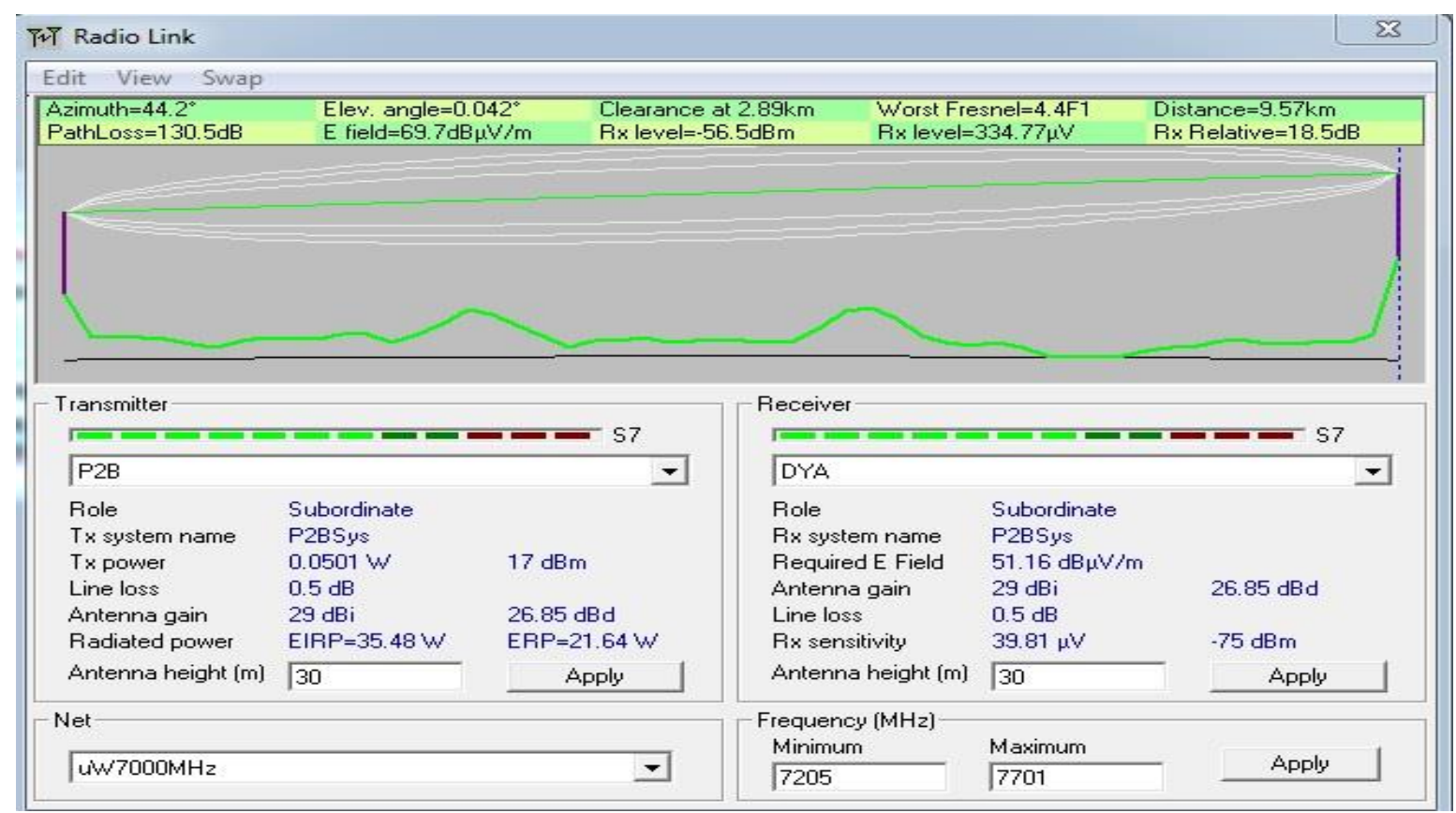

Gambar 2. Link Budget AP2B ke GI Daya[12]

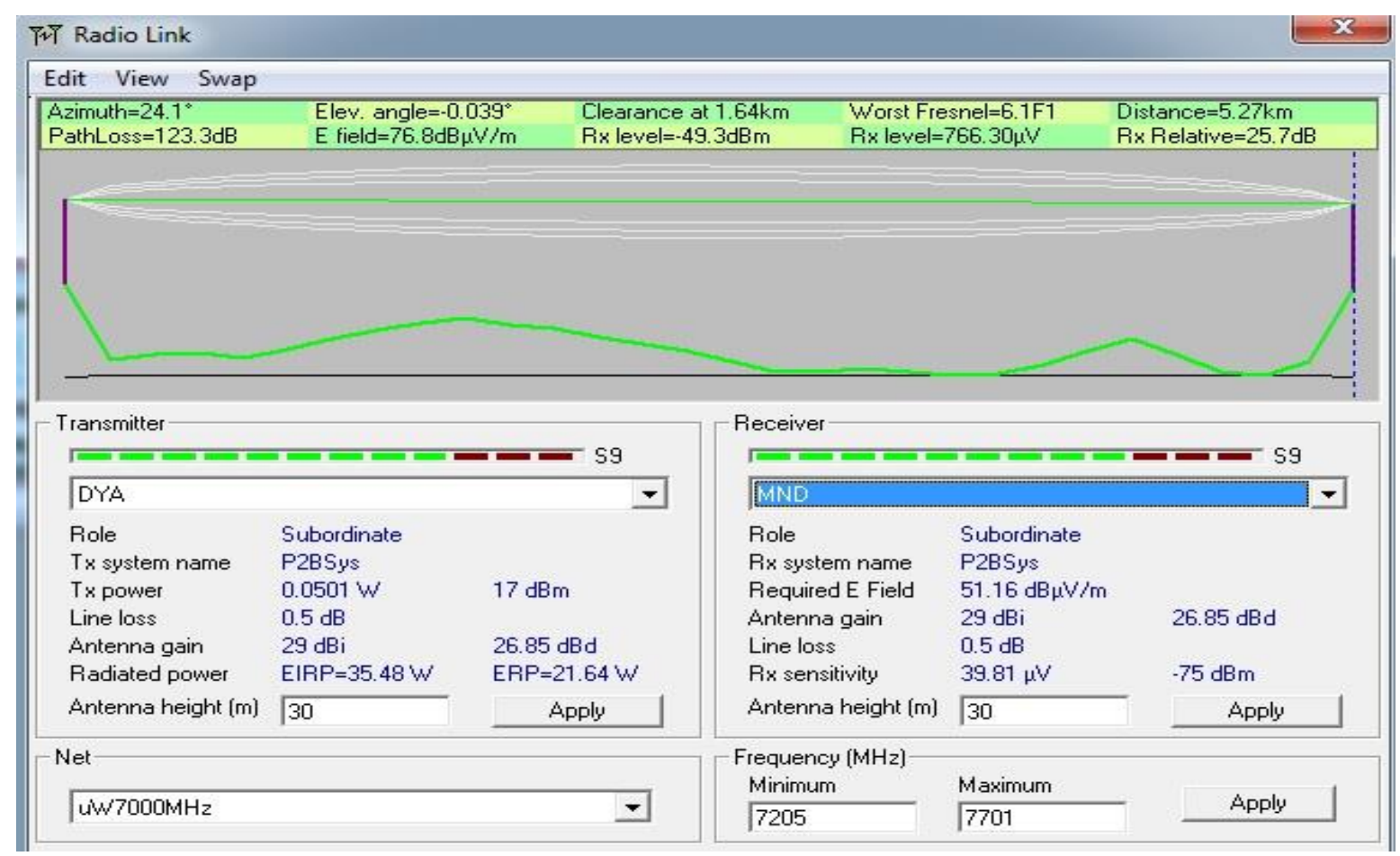

Gambar 3. Link Budget GI Daya ke GI Mandai[12] 


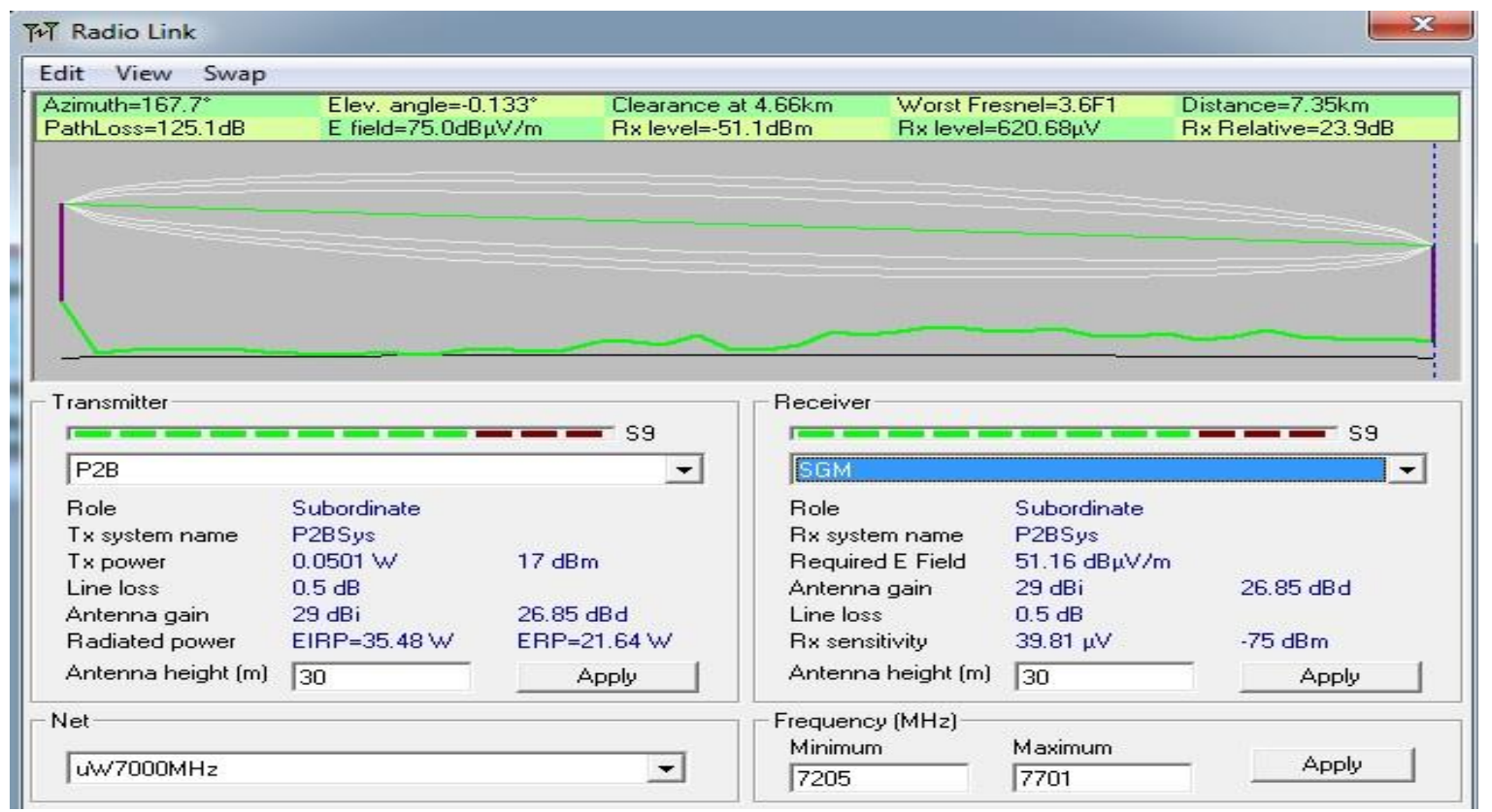

Gambar 4. Link Budget AP2B ke GI Sungguminasa[12]

Pembangunan radiolink microwave menambah jumlah kanal komunikasi antar gardu induk yang semula hanya 2 atau 4 (dengan menggunakan PLC), menjadi 120. Realisasi pembangunan dan data lokasi dijelaskan pada Gambar 5.

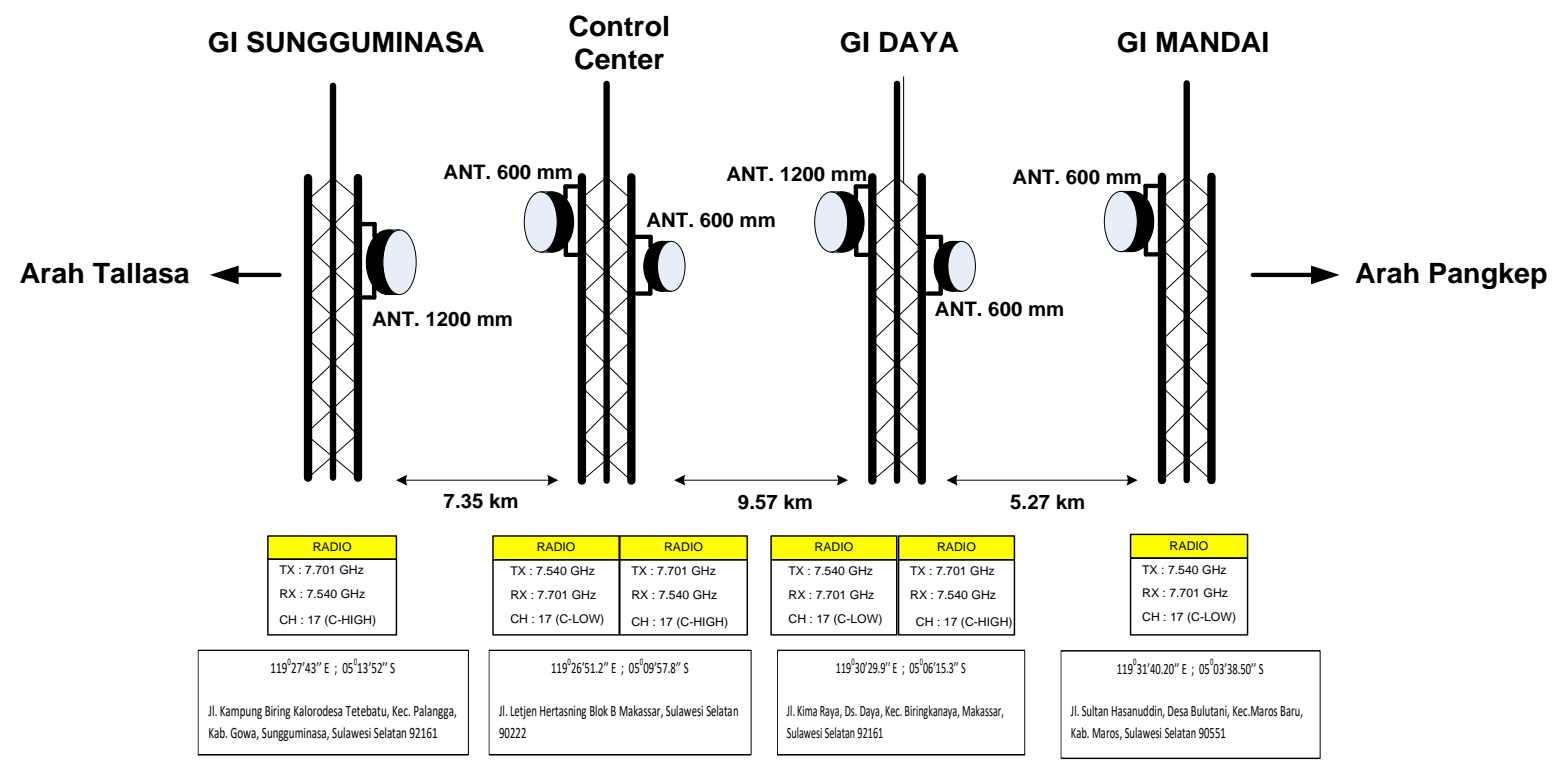

Gambar 5. Instalasi Radiolink Microwave

\section{Kesimpulan}

Pemanfaatan radiolink microwave meningkatkan jumlah kanal yang semula 4 kanal per link (PLC), menjadi 120 kanal per link (4E1). Pengembangan SCADA masih memerlukan survei dan studi ke arah Pangkep dan Tallasa. 


\section{KILAT}

Vol. 9, No. 1, April 2020, P-ISSN 2089-1245, E-ISSN 2655-4925

DOI: https://doi.org/10.33322/kilat.v9i1.767

\section{DAFTAR PUSTAKA}

[1] A. Z. Dodd, The Essential Guide to Telecommunications Sixth Edition, 6th ed. Pearson Higher Ed USA, 2019.

[2] G. Cancellieri, Single-Mode Optical Fibres. Elsevier Science, 2014.

[3] S. C. Basu, Fibre Optics Spark Technology. Notion Press, 2014.

[4] L. Blonstein, Communication Satellites. Elsevier Science, 2017.

[5] A. Z. Fradin, Microwave Antennas. Elsevier Science, 2017.

[6] B. R. Mehta and Y. J. Reddy, Industrial Process Automation System: Design and Implementation. Elsevier Science, 2014.

[7] P. Jarry and J. N. Beneat, Digital Communications. Elsevier Science, 2015.

[8] R. Medical, Amateur Radio Quick Study Guide. Rogue Medical, 2019.

[9] M. K. dan I. Republik Indonesia, Peraturan Menteri Komunikasi dan Informatika Republik Indonesia Nomor 33 tahun 2015 tentang Perencanaan Pita Frekuensi Radio Microwave Link Titik ke Titik (Point-to-Point). Kementerian Hukum dan Hak Asasi Manusia Republik Indonesia, 2015.

[10] M. K. dan I. Republik Indonesia, Peraturan Menteri Komunikasi dan Informatika Republik Indonesia Nomor 9 tahun 2018 tentang Ketentuan Operasional Penggunaan Spektrum Frekuensi Radio. Kementerian Hukum dan Hak Asasi Manusia Republik Indonesia, 2018.

[11] M. K. dan I. Republik Indonesia, Peraturan Menteri Komunikasi dan Informatika Republik Indonesia Nomor 6 tahun 2016 tentang Penyelenggaraan Telekomunikasi Khusus Untuk Keperluan Instansi Pemerintah Atau Badan Hukum. Kementerian Hukum dan Hak Asasi Manusia Republik Indonesia, 2016.

[12] R. Coude, "https://www.ve2dbe.com/english1.html," 2019. [Online]. Available: https://www.ve2dbe.com/english1.html. 